\title{
Direito Social: denominação, conceito e conteúdo
}

\author{
(Aula inaugural do curso de Legislação Social)
}

Cesarino Junior

\section{A EXPRESSÃO "DIREITO SOCIAL"}

\author{
Sumário - 1 Diversas denominações. 2 - Direito Ope- \\ rário. 3 - Legislação do Trabalho. 4 - Direito \\ Social. 5 - Direito Corporativo. 6 - Direito ou \\ Legislação?
}

1 - A disciplina jurídica que faz o objeto desta cadeira não é igualmente denominada pelos tratadistas. Assim, enquanto uns, como o programa da Faculdade de Direito da Universidade de São Paulo, a batizam de Legislação Social (1), outros, como o da sua congênere da Capital Fe-

(1) Arcá, Legislazione Sociale, in Primo Trattato di Diritto Administrativo, de Orlando, vol. IV, P. I, Milão, 1928; PoBletr Trancoso, La Legislation Sociale dans L'Amérique Latine, Revue Internationale du Travail, 1928, XVII; BRANQ JASSy, La Legislation Sociale en Roumanie, Bucarest, 1926; Argoncillo Sevilia, Manual de Legislacion Social, Malaga, 1933; Francisco Alexandre, Estudos de Legislação Social, Rio de Janeiro, 1930; Ministerio do Trabalho Legislation Sociale Brésilienne, Rio de Janeiro, 1937; A. CiAstroviejo, La Legislacion Social, Granada, 1902; WALdemar Ferreira, Principios de Legislação Social e Direito Judiciário do Trabalho, S. Paulo, 1938. 
deral, a chamam apenas de Legislação do Trabalho (2). A Constituição de 10 de novembro de 1937, no art. 16, n..$^{\circ}$ XVI, fala em Direito Operário (3), enquanto no art. 137 emprega a denominação Legislação do Trabalho e no art. 139 a de Legislação Social. 0 decreto-lei n. $^{\circ} 1237$, de 2 de maio de 1939 que instituiu a Justiça do Trabalho, no art. $10^{\circ}$ se refere a Legislação Social e no art. 94 a Direito Social. Parece, pois, que para o nosso direito positivo essas expressões são sinónimas.

Outros autores preferem as expressões Direito do Trabalho (4), Direito Corporativo (5), Direito Social (6) e Di-

(2) ANgelelli, Principii di Legislazione del Lavoro. Roma. 1938; Balella, Lezioni di Legislazione del Lavoro, Roma, 1927; Fossati, Corso di Legislazione del Lavoro, Torino, 1929; Melone, La nuova legislazione del lavoro e la sua posizione nel sistema delle discipline giuridiche, in Arch. Giur. 1928; W. Niemeyer, Curso de Legislação Brasileira do Trabalho, Rio de Janeiro, 1936; Bezerra de Freitas, Legislacão do Trabalho e Previdencia Social, 1938; Massè, BovierlaPERRE, Legislation du travail et prévoyance sociale, Paris, 1927; PosaDA, La Legislacion del trabajo, 1935; Common e Andrews, Principles of Labor legislation, Nova York, 1936; BABEr, La legislation du travail en Suisse, in Mélanges Mahaim, Paris, 1935; Pap, La legislation du travail en Hongrie, Revue internationa!e du travail, 1923; ARENA, Corso di Legislazione Comparata del Lavoro, Pisa, 1929; Mazzonr, idem, Milão, 1936; Carvalho Neto, Legislação do Trabalho, Rio de Janeiro, 1926; Cardoso DE Oliveira, Noções de legislação da Previdência $e$ do Trabalho, Pio de Janeiro, 1937; Santoro Passarelli, Legislazione del lavoro, Padua, 1934; L. Franchi, Nozioni di legislazione del lavoro e della prevideza sociale, Turim, 1930.

(3) Cohendy Grigaut, Legislation ouvrière, Paris, 1930; DupiN e Desvaux, Précis de legisiation ouvriére et industrielle, Paris, 1925; Scelle, Le droit ouvrier, Paris, 1929; M. Alvarez, Derecho Obrero, Madrid, 1933; G. Blanco Santa Maria, Derecho Obrero, 1933; Evaristo De Mopars, Apontamentos de Direito Operário, Pio de Janeiro, 1905.

(4) Asquini, Sull'àutonomia del diritto del lavoro, Archivo Giuridico, 1926, XCV; Barassi, Il Dirittı del lavoro, Milão, 1935; Diritto Corporativo e Diritto del Lavoro, Milão, 1939; Bellone, Diritio del Lavoro, in enciclopedia giuridica italiana, 1937; Bontolotro, Il diritto del lavoro, Milão, 1935; Riva Sanseverino, Corso di diritto del lavoro, Pádua, 1938; Marrosu, Sul concetto di diritto del lavoro italiano, in il Diritto del lavoro, 1937; LEDERER, Grundriss des Arbeitsrechts, Wien, 1929; Fernegg, Handbuch des Arbeitsrechts, Praga, 1931; Grow, Deutsches Arbeitsrecht, 1924; KaSKEL-Densch, Arbeitsrecht, Berlim, 1932; Hueck NipPerdey, Lehrbuch des Arbeitsrechts, Berlim, 1936; Nikisch, Arbeitsrecht, Tubingen, 1936; PorrHofr, Arbeitsrecht, Leipzig. 1931; SAyre, Case of Labor Law, Cambridge University, 1922; MoK, Arbeitsrecht, 1936; Danilova, Diritto sovietico del lavoro, Roma, 1930; Bradley, Elements of Labor Lav, Nova York, 1920; A 
reito ou Legislação Industrial (7). É de notar, entretanto, que nem todos dão à nossa disciplina o mesmo conteudo, o que, muitas vezes, explica a diversidade de nomenclaturas. Nos parágrafos seguintes examinaremos essas divergências.

Por enquanto, diremos apenas que, por Legislação Social, se entende geralmente o "conjunto das medidas legais e regulamentares, visando a proteção dos salariados, de um modo particular, e, de um modo geral, de todas as classes desprotegidas da sociedade"

2 - Essas medidas de proteção tiveram início principalmente tendo em vista resolver a chamada questão social, pelo melhoramento das condições dos trabalhadores, notadamente dos operarios, isto é, dos trabalhadores manuais,

Galiart Forch, Derecho Español del Trabajo, Barcelona, 1936; Ramirez Gronda, Derecho del Trabajo, Buenos Aires, 1938; Mario de LA Cueva, Derecho Mexicano del Trabajo, Mexico, 1938; Helvecio Xavier Lopes, Soluçôes práticas de Direito do trabalho. Rio de .Janeiro, 1938; SinzheIMER, Grundzüge des Arbeitsrechts, Iena, 1927; Herscher, Neues Arbeitsrechts, Leipzig, 1937.

(5) O. Fantrni, Legislazione Corporativa del Lavoro, Milão, 1938; Chrarelli, Il Diritto Corporativo e le sue fonti; Cesarini-SforzA, Corso di Diritto Corporativo; Crofri, Instituzioni di Diritto Corporativo.

(6) F. Ayala, El Derecho Social en la Constitucion de La Republica Española, Madrid, s/d; C. Bernaldo de Quiris, Derecho Social, Madrid, 1932; F. Bergamin, Derecho Social, Madrid, 1932; G. Garcia Oviedo, Tratado elementar de Derecho Social, Madrid, 1934; L. MarTin Granizo e M. Gonzalez Rothvoss, Derecho Social, Madrid, 1934; Gomez de Marcado e De Miguel Francisco, Politica y Derecho Social de España, Madrid, 1935; Guillaume Desouches, Le Nolveau Droit Social, Paris, 1938; Georges Gurvitcir, L'idée de Droit Social, Paris, 1932; Le temps present et l'idèe du droit social, Paris, 1932; Gonzalo de Reparaz, Derecho Social; Paul Pic, Le centenaire du code civil at le droit social de demain, (Quest. pratiques, 1904).

(7) Velge, Elements de Droit Industriel Belge, Bruxelles, 1928; BRY, Cours Elementaire de Legislation Industrielle, Paris, 1921; CAPItant et Cuche, Précis de Legislation Industrielle, Paris, 1936: PaUl PIc, Traité élementaire de legislation industrielle, Paris, 1933; Greenwoon, Hand book of Industrial Law, Londres, 1916; Tyllard, Industrial Law in India, Bombaim, 1933; Adauto Fernandes, Direito Industrial Brasileiro, Rio de Janeiro, 1938; Paul Haidant, Précis de Legislation Industrielle et Sociale, Liége, 1935. 
das fábricas e usinas, cuja condição era a mais carecedora do amparo oficial. Dai que alguns autores, principalmente francêses, espanhóis e argentinos empreguem a expressão Direito Operário para denominar a nossa disciplina. Entretanto, si essa denominação se podia explicar no seu inicio, hoje ela não tem mais razão de ser, pois as mesmas medidas de proteção, antes concedidas aos operários, se extenderam na atualidade, consideravelmente melhoradas, a outras classes de trabalhadores, como os técnicos e intelectuais, e não só da indústria, como tambem do comércio e da agricultura. É, por isto, inaceitavel a expressão “Direito Operário", como demasiadamente restrita. O mesmo se diga da expressão "Direito lndustrial" hoje reservada às questões da propriedade industrial (patentes de invenção, marcas de fábrica, nome comercial, etc.). Tanto isto é assim que em todas as Faculdades de Direito do Brasil, com exceção da de São Paulo, o Direito Industrial é ensinado à parte da Legislação do Trabalho, embora reunidos ambos na mesma cadeira, sob a denominação dupla de "Direito Industrial e Legislação do Trabalho" ad instar do sistema geralmente seguido pelas congêneres francesas. Na Faculdade de Direito da Universidade de São Paulo, o Direito Industrial è ensinado juntamente com o Direito Comercial, de que deriva, o que julgamos muito mais acertado.

3 - Mais felizes seriam o nome de Legislação do Trabalho ou os equivalentes de Legislação Trabalhista e Direito Laboral, pois permitem abranger todos os trabalhadores. Mas, ainda contra êles se levantam objeções. Diz-se, por exemplo, que a nossa disciplina se ocupa também de situaçōes não propriamente referentes aos trabalhadores, como as normas relativas às restrições impostas ao direito de propriedade, no interesse coletivo, as disposições sobre educação social, amparo aos necessitados, aos menores, às mulheres, à pequena propriedade, etc. Tal é, por exemplo, a extensão dada à matéria pelo programa da Faculdade de 
Direito de São Paulo, que faz da Legislação Social o estudo de quasi toda a atividade social do Estado.

4 - A expressão Direito Social, assim como a de Legislação Social, incidem na arguição de que todo direito é naturalmente social, por isso que não póde haver direito senão em sociedade. Ubi societas, ibi jus. A ela respondem os seus partidários, observando que a expressão "social", na denominação da nossa disciplina, visa opô-la ao direito individualista, oriundo da Revolução Francêsa, significando a predominância do interesse coletivo sôbre o individual. Pensamos que têm razão, embora "todo o direito" hoje se socialize, como tão bem o têm demonstrado, entre outros, os professores Le Fur, (8) Josserand (9) e Radbruch (10). E que, a-pesar-do sentido social, da "humanização do Direito" ser comum a todos os seus ramos, esse sentido social se acentuou sobremodo, diriamos até, se concentrou, neste ramo dos conhecimentos jurídicos a que uns chamam Legislação e outros, melhormente, Direito Social.

Ademais, visando este ramo do Direito, como veremos logo mais, ao abordarmos seu conceito, restabelecer o equilibrio "social", resolvendo a chamada questão "social", muito lógico nos parece que se lhe dê exatamente este qualificativo de "Social", uma vez que todo equívoco desaparece, dado o sentido especial que a palavra tem atualmente. Este sentido foi posto em relêvo pela definição de "serviço social" aprovada na 1. Conferência Internacional de Serviços Sociais: "O serviço social compreende todo e qualquer esfôrço que tenha por objetivo minorar os sofrimentos oriundos da miséria, e reconduzir tanto o indivíduo, como a familia, na medida do possivel, às normas de existência do meio em que habita" (11)

(8) Droit individuel et droit social, in Archives de Philosophie du Droit et Sociologie Juridique, 1934, pag. 34.

(9) Evolutions et actualités, Paris, 1937, pg. 159 e segs.

(10) Introducion a la ciencia del Derecho, Barcelona, 1932 pg. 108 e segs.

(11) Prof. A. C. Pacheco E Silva, Serviços sociais, S. Paulo, 1938, pg. 13. 
Arcí define a Legislação Social: "o conjunto de normas emanadas do Estado, disciplinando as relações que intercedem entre as classes capitalistas e as classes trabalhadoras", (12) acrescentando: "Social se diz essa legislação, seja porque se refere a relações entre classes ou entre individuos de classe diversa, seja porque não tem atitudes, caracteres, e fins jurídicos, mas sim de tutela e proteção, de disciplinamento de situações de fato e de relações sociais extra-judiciais, as quais superam e em parte contradizem a premissa da absoluta igualdade de direito, que é imprescindivel à compreensão das relações judiciais de direito privado e a noção de sujeição que tambem é imprescindivel à compreensão das relações que prendem o individuo de qualquer classe ao Estado"

Garcial Ovideo diz, a respeito: "Histórica e racionalmente brotou este direito da necessidade de resolver o chamado problema social, surgido pela rutura dos quadros corporativos e nascimento da grande indústria e, com êle, do proletariado, acontecimento que gerou a luta de classes, isto é, a luta social. Social é, pois, o conteudo do problema e social deve ser o direito criado para a sua resolução"

5 - Para nós não pode ser exato o nome de "Direito Corporativo" Este, como, para a Itália observa Borsi (13), “é a disciplina da organização sindical dos empregadores e empregados e da harmônica coordenação das forças produtivas, tipicamente própria dos Estados do tipo italiano, que por isso mesmo são chamados "Estados Corporativos". De acôrdo com esta definição o Direito Corporativo seria, por um lado, mais restrito que o Direito do Trabalho, por versar, quanto às regras concernentes aos trabalhadores, apenas as que se referem à sua organização sindical, e, por

(12) Legislazione Sociale, no Trattato di Dirito Amministrativo Italiano, de Orlando, vol. IV, apud Mario Guimarães de Souza, Objeto e Limites da Justiça do Trabalho, Recife, 1937, pg. 104.

(13) Legislazione Sociale del Lavoro, Milão, 1938, pg. 5 e 6. 
outro lado, mais amplo, por compreender a harmonização de "todas" as fôrças da produção e não sòmente as do trabalho. Pensamos, como o referido autor, que ele apenas deve dar ao Direito do Trabalho os seus principios fundamentais, por isso que é um ordenamento transcendente em relação a este, mas o incluimos no Direito Social, como uma de suas partes apenas (V. infra $n .^{\circ} 22$ ).

6 - Direito ou Legislação? Em regra se prefere a denominação de Legislação Social, como fez o dec. estadual n. ${ }^{\circ} 3023$, de 15 de julho de 1937, que criou a cadeira na Faculdade de Direito de São Paulo, talvez por se tratar de uma disciplina nova, que se tem receio de considerar perfeitamente, ou melhor, completamente formada. Preferimos, porém, a denominação de Direito Social, significativa de não se tratar apenas de uma coleção empirica de dispositivos legais, mas de um complexo orgânico de princípios e normas, cuja autonomia está hoje perfeitamente assentada, conforme veremos a seu tempo. Aliás, cumpre lembrálo tambem, a Constituição de 10 de novembro, no art. 16, $\mathrm{n}$. VI, coloca o "direito" operário ao lado do "direito" civil, do "direito" comercial, do "direito" judiciário, etc. Daí o preferirmos a expressão Direito Social.

II

\section{DEFINIÇAO DE DIREITO SOCIAL}

SumArio: 7 - Maltiplieidade de conceitos de Diretio Social. 8 - Correspondência entre os diversos conceitos e as denominações da diseiplina. 9 - Enunciação dos principais conceitos. 10 - Sua crítica. 0 verdadeiro método a seguir. 11 - Conceito amplo de Legislação do Trabalho, e Direito Soeial. 12 - A Constituiȩão Brasileira e a proteção ao economieamente débil. 13 - Essa proteção e a igualdade perante a lei. 14 - Fim principal do Direito So- 
cial: assegurar a paz social. 15 - Conceito de trabalhador em direito social. 16 - Necessidades vitais 17 - Carater supletivo das leis sociais. 18 - Finalidade supraeconômica das leis sociais. 19 - Definição de Direito Social. 20 - Análise desta definięão.

7 - Riccardo Marrosu, inteligente escritor italiano, num esplêndido artigo para a revista "Il Diritto del Lavoro", que se intitula "Sul concetto del Diritto italiano del lavoro" começa por afirmar, e com inteira razão, que a perplexidade, a incerteza e a confusão sobre as linhas principais, as questões fundamentais e o modo de entender os novos campos de investigação geram quasi sempre o ceticismo sobre a legitimidade científica da nova ordem de conhecimentos. E' este exatamente o caso do Direito Social, ao qual se deu o nome em certo modo pejorativo de Legislação Social e do qual já disse alguem, com muito espírito, mas com pouca exatidão, que não possa de méra "perfumaria jurídica" Entretanto, os mesmos males se apresentaram no início das ciências hoje constituidas, devido à diversidade de pontos de vista, quanto ao seu objéto, aos seus princípios e aos seus critérios metodológicos.

Quanto ao Direito Social é, portanto, naturalmente compreensivel a diversidade, não sómente de denominações, como de conceitos, visto como se trata da mais nova de todas as disciplinas jurídicas.

8 - Como o Direito Social se criou para resolver as questóes surgidas com o aparecimento da grande indústria, entre patrões e operários, teve êle a principio os nomes de Direito Industrial e de Direito Operário, com as correspondentes finalidades de regular as relações oriundas desses problemas. Entretanto, a grande expansão que tiveram as leis reguladoras das relações entre o capital e o trabalho, em todo o mundo, no segundo quartel do presente século, e especialmente na Itália, depois do advento do regime fascista, 
fizeram com que se passasse a denominar o novo direito, de Direito ou Legislação do Trabalho, por isso que êle abrangia novas formas do trabalho que não as puramente industriais, aplicando-se não sómente aos operários das fábricas e usinas, mas tambem aos trabalhadores técnicos e intelectuais. Mas, ao mesmo tempo, cumpria verificar que as primeiras conquistas da classe trabalhadora tinham sido obtidas por intermédio de sua organização nos sindicatos trabalhistas, que, por sua vez, provocaram a formação dos sindicatos patronais, unindo-os depois o regime fascista nas corporações. Assim, estas uniões de trabalhadores, a princípio combatidas, depois toleradas, enfim legalizadas, se transformaram afinal em verdadeiros órgãos do Estado fascista. Daí uma nova denominação para o novo corpo de leis, a de Direito Sindical e Corporativo, ou mais abreviadamente, Direito Corporativo. Entretanto, a lembrança da sua origem na solução da "questão social", nas dúvidas entre as "classes sociais", não deixava de influir para que se désse, ao novo direito, tambem a denominação de Direito ou Legislação Social. Vê-se, portanto, que a cada uma destas denominações correspondeu um conceito da disciplina, conceito êste mais ou menos consonante com o progresso por ela atingido e com a extensão do campo de sua aplicação.

9 - Ao proceder-se, entretanto, á elaboração doutrinária referente à nova legislação era mistér adotar-se um nome e fixar-se um conceito para ela. Quais seriam? A citada revista “Il Diritto del Lavoro", criada em 1927, na Itália, como órgão oficial do Ministério das Corporações, procedeu a um inquérito a respeito entre os juristas italianos. Como era de esperar-se, não se chegou a um acôrdo. Entretanto, prevaleceu, para a revista, a denominação de "Diritto del Lavoro", por se entender que o trabalho era o elemento mais caracteristico de toda a nova legislação. Quanto aos conceitos, variaram desde o de Asqurni, que reduz o Direito 
do Trabalho ao "complexo de normas que regulam o trabalho prestado em virtude de um contrato na dependência de uma empresa privada", até o de Lessona, que dá ao Direito do Trabalho um objéto que compreende a organização e o processo jurisdicional do trabalho, a administração pública das relações de trabalho, as relações entre as associações e os associados, de modo que o Direito do Trabalho absorveria o direito corporativo e o direito processual do trabalho. E de permeio ficariam os conceitos de BARAssI, aproximado do de Asqunn, de Pergolesi, que compreende no campo do Direito do Trabalho, além do contrato individual de trabalho, tambem as relações de emprego público e de caracter profissional, e a de FANTINI, para quem o Direito do Trabalho é o complexo das normas que tendem à disciplina e à tutela do trabalho. Citamos sómente autores italianos, não só porque a maioria dos escritores de outras nacionalidades evita dar uma definição precisa da matéria versada, como, por exemplo, Paul Pic, Georges Scelle, CaPitant e Cuche, ou então nos dá uma das definições já apontadas entre os escritores italianos, como Gallart Folch, que define: "Entendemos por Direito do Trabalho o conjunto de normas juridicas dirigidas a regular as relações de trabalho entre patrões e operários e, ademais, outros aspectos da vida destes últimos, mas precisamente em razão de sua condição de trabalhadores", ou Radbruch, para quem o Direito operário é "uma disciplina nova que focaliza as relações econômicas sob o critério da proteção do debil em frente ao poderoso endinheirado" Dos autores brasileiros não falamos porque até agora não conhecemos nenhum original.

E, por que essa diferença entre os escritores? Porque, todos êles dão definições mais ou menos apriorísticas, mais ou menos subjetivistas da nossa disciplina, esquecidos da lição tão certa e proveitosa lembrada por MARrosu: a primeira coisa a fazer é determinar o objeto da observação, fixar, de um modo científico, porém, o conceito da nova ciência, como indispensavel exigência lógica. 
10 - Até aqui as definições dadas ao Direito do TrabaTho têm um processo de formação essencialmente dogmático. Deduz-se o seu conceito de pressupostos já fixados, que não se discutem, como Barassi, que parte do pressuposto jusnaturalista, de que o direito se exaure no negócio juridico; outros, da visão teleológica do reforçamento da nação. São os dois grupos em que se pódem dividir os autores citados acima: privatistas e publicistas ou corporativistas. Daí que cada um tenha um ponto de vista irredutivel. Eles opõem uns aos outros, opinião a opinião, sem nenhuma base positiva. Assim são subjetivistas, quando o rigor científico exige a objetividade, isto é, o ponto de vista pelo qual se deve considerar o objeto, deve depender, não de nós, mas do próprio objeto estudado. Não se deve, porém, partir de um sistema já construido. Assim não se deve usar o método dedutivo, mas o indutivo. "O conceito que deve determinar-se resulta constituido por diversos elementos, que são por sua vez conceitos parciais, os quais com o seu conteudo especifico e com as suas relações, dão o conteudo geral do conceito procurado". Estes conceitos subordinados dão origem a uma série de pesquizas particulares. Assim podemos perguntar-nos qual seja a nota comum que, na multiplicidade das normas juridicas, diferencia aquelas que vão formar um campo distinto; como tal distinção se tenha produzido; se corresponde ou não a determinadas condições histórico-sociais; quais os fins procurados; se inovou ou não na ordem jurídica e no sistema científico.

A primeira pesquiza é a síntese teorética, a determinaȩão lógica do objeto constitutivo do novo ramo, obtida com a especificação das normas jurídicas que nos apresenta a realidade, objeto de nossas pesquizas. Assim, segundo Kelsen, o conteudo jurídico-científico não póde ser obtido senão atravez o processo jurídico da atividade legislativa e executiva. Neste campo limitado, não se tende a individuar a forma universal da juridicidade, mas toda uma série de noções que dizem respeito à concreção histórica de deter- 
minados institutos, de determinadas leis. Por isto, à pesquiza teorética do conceito lógico de um particular ramo juridico, deve unir-se a pesquiza da gênese e tambem a dos fins. Assim, não sómente se afirma o "jus quia jussum est", mas tambem o "jus quia justum est".

Nesta ordem de idéias, os dados devem ser, não os conceitos jurídicos já elaborados pela doutrina, mas a norma juridica, não já unida em conceitos, mas como póde encontrarse na produção legislativa, ainda não recolhida e sitematizada em conceitos doutrinários. Assim: 1) colheita de dados; 2) seu confronto; 3) determinação das semeIhanças e das diferenças; 4) abstração das notas comuns.

O precedente da formação dos conceitos é que a língua tenha classificado os objetos, mediante os nomes, que à comparação refletida e conciente, tenha precedido a espontânea e inconciente, à ciência, a intuição.

$O$ direito, antes que na elaboração cientifica, vive no ordenamento juridico. Assim, antes de saber o que é o Direito do Trabalho, afirma Marrosu, conhecemos sua existência afirmada pelo nome Direito do Trabalho que nos atesta que no ordenamento jurídico ha um conjunto de normas classificadas intuitivamente como normas jurídicas do trabalho. Até aqui seguimos fielmente a Ricardo Marrosu. Entretanto, é chegada a ocasião de, embora conservando o seu método, nos afastarmos dele. Com efeito, Marrosu, levado pelo fenómeno que já indicamos da preeminência que nos primeiros tempos do direito novo tiveram os trabalhadores, se deixou impressionar exclusivamente pela expressão Direito do Trabalho, olvidando que o novo direito abrange na sua esfera de aplicação tambem individuos qut propriamente não se pódem chamar de trabalhadores, pelo menos no sentido restrito dado geralmente a este termo, pois inclúe, como entre outros já notou PAUL PIc, tambem os pequenos burgulezes, os artezãos, etc. E o proprio Papa LEÃo XIII, na Rerum Novarum, diz que: "os trabalhadores 
pertencem á classe pobre em geral" Assim, o direito novo não é apenas o Direito do Trabalho: este é apenas, como veremos logo mais, uma de suas partes. O direito novo é o Direito Social. Tanto ou mais que para o direito do trabalho, a linguagem comum afirma a sua existência, pois é raro o autor que escrevendo sobre a nova disciplina, seja qual fôr o conceito que siga ou a denominação que adote, não fale em Legislaçâo social ou pelo menos em leis sociais. Isto posto, continuemos com Marrosu, mutatis mutandis.

$\mathrm{O}$ nome nos dá a noção intuitiva do objeto. Não ha dúvida de que tal noção não seja suficiente para um conhecimento científico, mas é já um dado ancorado em nossa consoiência. Na passagem da noção ao conceito, do pensamento imediato ao pensamento mediato consiste o processo científico em virtude do qual poderemos dizer, não só que uma coisa é, mas tambem que coisa é. Entre noção e conceito não ha diferença quantitativa, mas qualitativa, de grau de saber, que se aprofunda e penetra no interior da conciência, deixando identico o objeto do conhecimento. Toda investigação científica parte da definição verbal para chegar á definição real, pois antes de procurar definir uma coisa é preciso ter dela uma idéia qualquer e distinguí-la claramente das outras. Si o conteudo do conceito resultar idêntico ao da noção, deverão excluir-se as definições que dão ao Direito Social um conteudo mais ou menos extenso que o da noção.

Não se pode contestar que o Direito Social existe (dado de fato positivo) quando mais não seja pelo uso constante que se faz desta expressão, da de Legislação Social e da de leis sociais. Ha no ordenamento jurídico normas que visam estabelecer o equilíbrio social, pela proteção aos economicamente fracos. Assim a idéia que a expressão “Direito Social" nos evoca é a de um complexo de normas tendentes á proteção dos economicamente débeis. Assim basta examinar qualquer das regras referentes ao trabalho de 
menores, à duração do trabalho, aos acidentes do trabalho, à rescisão do contrato de trabalho, à repressão da usura, à organização e funcionamento dos sindicatos, para vermos que todas elas se destinam à proteção dos indivíduos economicamente débeis. Mas não basta conhecer normas individuais de Direito Social: é preciso conhecer a norma de Direito Social. É preciso, ao escolher uma norma de Direito, como de Direito Social, poder dizer porque se escolhe. É preciso compará-las, para vêr os elementos comuns e os diferentes, sendo que a união dos primeiros nos dará a essência da norma de Direito Social. Na norma jurídica se distinguem três elementos: 1) a forma, que a diferencia das outras normas de conduta, como uma ordem coativa proveniente do poder; 2) o conteudo formal, dado pelo modo por que a norma regula as relações; 3) o conteudo material, constituido pelas relações reguladas, o objeto da norma.

$O$ conteudo material referente às normas estudadas mostra que idêntico é o seu conteudo, idêntica a gênese, idêntico o fim. Si igual é a essência devemos lógicamente concluir que todas as normas confrontadas fazem parte de um mesmo campo, mesmo si tradicionalmente, por condições acidentais e contingentes e, especialmente porque ainda não se distinguiam os seus caracteres comuns e não se advertia a sua necessidade, eram colocadas em ramos separados. É a lei universal da evolução que se manifesta através da unidade (a falta de necessidade de distinção deixa que as normas jurídicas sociais não percebidas sejam compreendidas em outros corpos de leis); diferença (enquanto se sente a importância econômico-social da proteção ao económicamente fraco as normas jurídicas aumentam de número e se diferenciam dos corpos a que estavam unidas); unidade dos diferentes (com o progresso se tem a síntese: as normas agora desprendidas, diferenciadas, se unem formando um só corpo próprio). 
11 - Mesmo a denominação de "Legislação do Trabalho" se póde tambem entender em sentido amplo, como nos ensina Borsi, compreendendo: "normas de direito privado, como as do Código Civil, sobre o contrato de locação de serviços e as relativas ao contrato de emprego privado (isto na Italia) e normas de direito público, como as sobre organização e ação sindical e corporativa e as sobre tutela física, moral e econômica dos trabalhadores" Assim sendo, a Legislação do Trabalho diferiria do Direito Social, apenas no fato da primeira se referir tão sòmente aos trabalhadores, enquanto a segunda abrangeria tambem, no campo de sua aplicação, a outros indivíduos. Isto concorda com o fim das leis sociais, que é a proteção aos individuos economicamente fracos, sejam trabalhadores ou não, isto é, àqueles de quem se póde dizer que representam, segundo LEão XIII, na Rerum Novarum "a fraqueza na indigência" As leis sociais visam, como dis muito justamente Gallart Folch, "compensar com uma superioridade juridica, a inferioridade econômica",

12 - Assim, a Constituição, em vários dos seus dispositivos deixa entrever claramente esta finalidade imediata das leis sociais: a proteção ao economicamente fraco. Bastaria recordar o art. 124: "A família, constituida pelo casamento indissoluvel, está sob a proteção especial do Estado. Às familias numerosas serão atribuidas compensações na proporção de seus encargos"; o art. 125: "A educação integral da prole é o primeiro dever e o direito natural dos pais. 0 Estado não será estranho a esse dever, colaborando de maneira principal ou subsidiária, para facilitar a sua execução ou suprir as deficiências e lacunas da educação particular; o art. 127 in fine: "Aos pais miseráveis assiste o direito de invocar o auxílio e proteção do Estado para a subsistência e educação da sua prole; o art. 129: “À infância e à juventude, a que faltarem recursos necessarios à educação em

(14) Derecho Español del Trabajo, Barcelona, 1936, pg. 2. 
instituições particulares, é dever da Nação, dos Estados e dos Municípios assegurar, pela fundação de instituições públicas de ensino, em todos os seus graus, a possibilidade de receber uma educação adequada às suas faculdades, aptidões e tendências vocacionais. $O$ ensino prevocacional $e$ e profissional destinado às classes menos favorecidas é, em matéria de educação, o primeiro dever do Estado. Cumprelhe dar execução a esse dever, fundando institutos de ensino profissional e subsidiando os de iniciativa dos Estados, dos Municípios e dos individuos ou associações particulares e profissionais. É dever das indústrias e dos sindicatos econômicos criar, na esfera de sua especialidade, escolas de aprendizes, destinadas aos filhos de seus operários ou de seus associados. A lei regulará o cumprimento desse dever e os poderes que caberão ao Estado sobre essas escolas, bem como os auxílios, facilidades e subsidios a lhes serem concedidos pelo poder público; o art. 130: "O ensino primário é obrigatório e gratúito. A gratuidade, porém, não exclue o dever de solidariedade dos menos para com os mais necessitados"; o art. 136: "O trabalho é um dever social, o trabalho intelectual, técnico e manual tem direito à proteção e solicitude especiais do Estado. A todos é garantido o direito de subsistir mediante o seu trabalho honesto, e este, como meio de subsistência do indivíduo, constitue um bem, que é dever do Estado proteger, assegurando-lhe condições favoraveis e meios de defesa". Este mesmo escopo de proteção se nota ainda no art. 137, que especifica a forma que deverá ter a proteção ao trabalhador. - 0 art. 141, protegendo a economia popular, e o art. 142, declarando punivel a usura, vieram tambem beneficiar os individuos economicamente fracos.

13 - Ofenderá esta proteção aos fracos, ao princípio constitucional da igualdade perante a lei (art. 122, n. I) ? Evidentemente não, conforme ensina judiciosamente Aradjo Castro: "A expressão "todos são iguais perante a lei" deve ser entendida de maneira relativa, pois a igualdade 
absoluta é impossível. Os homens são iguais, já dizia ArIsTòTeles, se têm os mesmos direitos em idênticas condições. Segundo Marnoco e SouzA, a igualdade perante a lei significa que "em paridade de condições, ninguem póde ser tratado excepcionalmente e, por isso, o direito de igualdade não se opõe a uma diversa proteção das desigualdades naturais por parte da lei" (15).

Assim a Constituição Portuguesa de 33 declara: “A igualdade perante a lei envolve o direito de ser provido nos cargos públicos, conforme a capacidade dos serviços prestados, e a negação de qualquer privilégio de nascimento, de nobreza, de titulo nobiliárquico, sexo ou condição social, salvo quanto à mulher, as diferenças resultantes da sua natureza e do bem de família, e, quanto aos encargos ou vantagens dos cidadãos, as impostas pela diversidade das circunstâncias ou pela natureza das coisas".

“A igualdade, observa João Mangabeira, não é nem pode ser nunca um obstáculo à proteção que o Estado deve aos fracos. Consiste a igualdade, sobretudo, em considerar desigualmente condições desiguais, de modo a abrandar, tanto quanto possivel, pelo direito, as diferenças sociais e por êle promover a harmonia social, pelo equilibrio dos interesses e da sorte das classes. A concepção individualista do direito desaparece ante a sua socialização, como instrumento de justica social, solidariedade humana e felicidade coletiva" E adiante acrescenta o citado escritor: "A inscrição de normas de carater social e econômico, com o fim de assegurar os interesses do Estado para melhor assegurar os interesses da coletividade procurando, sobretudo, amparar as classes menos favorecidas da fortuna, constitúe a caraterística dominante das modernas Constituições"

Duguit reconheceu que incumbe ao Estado o dever de auxiliar aqueles que se acham impossibilitados de adquirir os recursos necessários à sua subsistência.

(15) A Nova Constituição Brasileira, Rio de Janeiro, 1938, pg. 267. 
A Constituição Alemã, no art. 63, dispôe: "Deve ser dado a todo alemão a oportunidade de ganhar a vida por meio de um trabalho produtivo. No caso em que não se possa proporcionar-lhe uma ocupação conveniente, serlhe-ão assegurados os necessários meios de subsistência"

0 mesmo dizia o art. 46 da Constituição da República Espanhola: "O trabalho em suas diversas formas é uma obrigação social e gozará da proteção das leis. A República assegurará a todo trabalhador as condições necessárias a uma existência digna"

14 - Mas, então - dir-se-à - o Direito Social é um direito de classe, um privilégio, e como tal injusto. Nada menos certo. O fim imediato das leis sociais é a proteção aos fracos, concordamos. Mas, não é o único. Por intermédio dessa proteção o que o Estado realmente visa é assegurar a paz social, o interesse geral, o bem comum. Isto, quanto ao direito brasileiro, está bem claro no art. 135 da Constituição, que dispõe: "Na iniciativa individual, no poder de criação, de organização, e de invenção do indivíduo, exercido nos limites do bem publico, funda-se a riqueza e a prosperidade nacional. A intervenção do Estado no domínio econômico só se legitima para suprir as deficiências da iniciativa individual e coordenar os fatores da produção de maneira a evitar ou resolver os seus conflitos, e introduzir no jogo das competições individuais o pensamento dos interesses da Nação, representados pelo Estado"

A mesma observação é feita quanto ao direito italiano por ANGelelli: "Só no período pre-fascista a finalidade da Legislação do Trabalho era a proteção dos fracos, maximé na estipulação ou na execução do contrato de trabalho, conceito este que até hoje têm, da finalidade da legislação do trabalho, alguns tratadistas, como Barassi e Balella. Entretanto, no período post-fascista, afastada a finalidade de defesa de classe, o princípio inspirador da Legislação do Trabalho passa a ser "o reforçamento qualitativo das fôrças de trabalho, como um aspecto da integridade da raça 
e da potência da nação" (16), e isto porque, segundo o art. 2 da Carta do Trabalho Italiano, "o trabalho é tutelado não por si, nem por fins genéricos de justiça ou de pacificação social, mas enquanto é um dever social. E é tal, porque é considerado como um meio concernente à potência da Nação".

Já vimos que o art. 136 da nossa Constituição tambem define o trabalho como um dever social, o que não impede lhe assegure o Estado a sua proteção.

15 - Aliás, conforme já dissemos, a oposição entre Legislação do Trabalho e Legislação Social, entendida a primeira no sentido amplo atrás enunciado, é apenas aparente, por isso que os individuos economicamente débeis são exatamente os trabalhadores: trabalhadores atuais, potenciais ou ex-trabalhadores. Efetivamente, em Direito Social, devemos entender por trabalhador - todo indivíduo que necessita do produto do seu trabalho para poder viver $e$ fazer viver a sua família. Assim sendo, mesmo o individuo que não trabalha, por uma impossibilidade física, como a doença ou invalidez; econômica, como o desemprêgo; ou moral, como a vadiagem (que, via de regra, é tambem uma doença) deve, neste sentido muito especial do termo, isto é, do ponto de vista do Direito Social, ser incluido no número dos trabalhadores e, portanto, dos beneficiários das leis sociais. Logo, só se devem excluir do campo do Direito Social, como protegidos por êle (como "protegidos", note-se bem, por isso que, sob outros aspectos, v. g., como "empregadores", êles entram no seu campo de aplicação) os individuos economicamente fortes, ou sejam os "remediados" e os ricos, os "autossuficientes" em suma.

Êste conceito amplo de "trabalhador" é autorizado pelo art. 136 da Constituição, ao dizer, que o "trabalho como meio de subsistência do individuo", "é protegido pelo Estado"

(16) Principii di Legislazione del Lavoro, Milão, 1938, pg. 17. 
16 - E, voltando ao nosso conceito especial de "traballhador", na expressão "viver" ali empregada, se devem subentender todos os aspectos de uma existência humana normal, isto é, alimentação, vestuário, habitação, transporte, higiene, educação e recreação condignos, ou melhor, medianamente satisfatórios, não só para o indivíduo, como para a sua família toda. Estes últimos aspectos, a educação e a recreação não foram contemplados pela lei que instituiu o salário mínimo (Lei n. 185, de 34, art. 1..$^{\circ}$ ), assim como a manutenção da família, por isso que, tendo em vista que se vai introduzir pela primeira vez o salário mínimo no Brasil, a lei só cogita do salário vital definindo-o:" "Denomina-se salário mínimo a remuneração mínima devida a todo trabalhador adulto, sem distinção de sexo, por dia normal de serviço, e capaz de satisfazer, em determinada época e região do país, as suas necessidades normais de alimentação, habitação, vestuário, higiene e transporte" (Art. 2..$^{\circ}$ do Regulamento aprovado pelo Decreto-lei n. 399, de 30 de abril de 1938).

17 - E' verdade que muitas medidas tomadas pelo Estado com carater geral beneficiam mesmo os individuos economicamente fortes, v. g. o saneamento de uma região insalubre. Mas, não sòmente já observamos que toda a atividade social do Estado não faz objeto do Direito Social, como tambem observaremos que, na generalidade dos casos, o fim imediato do Estado não foi beneficiar aos individuos autossuficientes, mas sim os economicamente fracos que, se não fôra o receio de introduzir muitos neologismos, ainda mais eivados de hibridismo, chamaria de hipossuficientes. E, como um ato deve caracterizar-se por seu fim imediato, e não pelos seus efeitos indiretos, essa observação não chega a contrariar, realmente, o nosso conceito. Com efeito, um característico que nos parece propriamente essencial nas leis sociais é o de serem supletivas (17), neste sentido ape- 
nas de que o Estado procura substituir-se, por meio delas, ao indivíduo hipossuficiente, para fazer aquilo que êle próprio, por sua fraqueza económica, não poderia fazer e que representa uma das necessidades vitais acima enumeradas. Frizamos bem o sentido todo espécial aqui dado à expressão supletivas, para que não se possa confundí-lo com o sentido comum da expressão, em Direito. Com efeito, geralmente se entendem por regras supletivas, em direito, aquelas disposições legais que só vigoram no silêncio dos contratantes, na ausência de disposições contratuais a respeito de um determinado assunto; e imperativas ou de ordem pública, as que vigoram sempre, não podendo ser contrariadas pela vontade das partes. Pois bem, é principio tambem essencial do Direito Social o conceito de ordem pública de todas as suas normas, por isso que, sendo elas instituidas em benefício dos economicamente fracos, mas no interesse supremo da paz social, este objetivo superior seria frustrado, si fosse lícito aos hipossuficientes renunciar a essa proteção.

Com efeito, o indivíduo autossuficiente se beneficia das vantagens do saneamento de uma região, da purificação da água para torná-la potavel, da limpeza das cidades, enfim, de diversos serviços prestados pelo Estado, mas êle não dependeria essencialmente deles para viver, por isso que, com os próprios recursos, lhe seria possivel procurar uma região mais salubre, servir-se de filtros ou de águas escolhidas, proceder por sua conta á limpeza do lugar de sua residência, etc.

18 - Nem se diga que o Direito Social não visa satisfazer apenas os indivíduos hipossuficientes, por isso que êle

(17) Sanseverino, - op. cit., pg. 16 - "O Direito do Trabalho é dominado por princípios gerais comuns às normas nele compreendidas e distintos dos princípios gerais informadores das outras disciplinas, qual, sobretudo, o principio da proteção do contraente economicamente mais iraco" 
não cogita unicamente da satisfação das necessidades materiais, preocupando-se tambem com os problemas da saúde do indivíduo, e da raça, da educação, da moralidade, etc. E' exáta esta preocupação superior do Direito Social, mas nem por isto é menos exato que as leis sociais visam fornecer ao indivíduo hipossuficiente os meios, geralmente econômicos, para que êle possa satisfazer essas necessidades físicas e imateriais e não puramente econômicas. Mas, não é menos verdade que êle obteria por si próprio esse meios, sem o auxílio das leis sociais, não fosse a sua debilidade econômica.

19 - Assim sendo, parece-me que se poderá definir: "Direito Social é o complexo dos princípios e leis imperativas, cujo objetivo imediato é, tendo em vista o bem comum, auxiliar a satisfazer convenientemente às necessidades vitais próprias e de suas famílias, aos indivíduos que, para tanto, dependem do produto de seu trabalho"

\section{0 - Analisemos esta definição:}

“Direito Social é o complexo dos princípios e leis imperativas. " - Sustentamos a autonomia científica do Direito Social, porque êle tem caracteres próprios, o principal dos quais é, como já acentuámos, o de ser supletivo das deficiências econômicas dos indivíduos por êle protegidos. Daí o considerarmos, ao mesmo tempo, um conjunto de princípios, como ciência, e um complexo de leis, como legislação. Aqui, a palavra "princípio" é empregada no sentido de lei científica e a palavra "lei", no de lei positiva, norma legal. Sobre o carater imperativo já nos explicamos.

“ .cujo objetivo imediato é auxiliar " - E' o carater supletivo, que faz com que o Direito Social vise diretamente (imediatamente) proteger os indivíduos hipossuficientes, e sobre o qual já insistimos bastante.

“ tendo em vista o bem comum. "- S. Tomaz já dizia que a lei é a "ordinatio rationis, ad bonum commune, 
ab eo qui curam habet communitatis promulgata" Si o cuidado pelo bem comum, é preocupação de toda lei, tanto assim que é elemento constitutivo de sua definição, com mais forte razão o é o das leis sociais, que visam estabelecer a paz social, auxiliando os hipossuficientes, a alcançar o equilíbrio econômico, social, moral e cultural na sociedade.

“ .. a satisfazer convenientemente às necessidades vitais próprias. " - Conforme tambem já mostramos, o homem para viver, necessita de: alimentação, vestuário, habitação, higiene (aqui incluidos tanto os cuidados para conservar a saúde, como para recuperá-la, sobrevinda a enfermidade), transporte, educação e recreação. São estas as necessidades vitais. Nem todos os homens, porém, podem, por si mesmos, satisfazê-las do mesmo modo: para uns, (hipossuficientes, ou economicamente fracos) há carência; para outros (autossuficientes ou economicamente fortes), abundância dos recursos precisos. O Direito Social visa proporcionar aos hipossuficientes um termo médio entre a carência de uns e a abundância de outros, um "quantum satis" (18). Este o sentido da expressão “ .satisfazer convenientemente.. ", empregada na definição.

“ .e de suas famillias. " - A expressão "família" é aqui empregada num sentido muito mais amplo que o comumente adotado, como o "conjunto das pessoas economicamente dependentes de uma outra, a que estão ligadas por laços de parentesco legítimo ou natural"

“ .aos indivíduos, que, para tanto, dependem do produto de seu trabalho. " - Novamente aqui o carater

(18) Cf. Sanseverino - Corso di Diritto del Lavoro - Cedam -. Padova, 1937, pg. 10 - "Nel resto questo concetto di legislazione sociale quale complesso di norme che, sanzionando la desiguaglianza e quindi l'antagonismo tra la classe dei datori di lavoro e quella dei lavoratori, vuole tutelare quest'ultima in quanto classe economicamente più débole, é sostanzialmente rimasto inalterato".

De notar que Sanseverino nâo admite este conceito para o direito italiano. Tambem RadBruch considera o Direito do Trabalho, como "uma medida de proteção do debil em frente ao poderoso". 
supletivo do Direito Social, que, como já se viu repetidas vezes, é fundamental em nosso sistema. Estes indivíduos correspondem perfeitamente à noção especial que demos do "trabalhador", como abrangendo todas as pessoas que precisam trabalhar para viver, embora não o façam, numa dada ocasião, seja por não poderem, seja por não quererem. $\mathrm{E}^{\prime}$ interessante notar que, nesta última hipótese, o auxílio das leis sociais poderia consistir em obrigar o indíviduo a trabalhar.

\section{III}

\section{DIVISÃO DO DIREITO SOCIAL}

Sumákio: 21 - Divisão do Direito Social. 22 - Direito Corporativo ou Direito Social Coletivo. 23 Direito do Trabalho ou Direito Social Especifico. 24 - Direito Social propriamente dito ou Direito Social Genérico. 25 - Esquema.

21 - Vejamos agora quais são estes principios e leis.

Si o Direito Social visa auxiliar os individuos que dependem do produto do seu trabalho, vê-se bem que, para êle, devem ter uma importância capital as questões ligadas ao trabalho. Deverá, portanto, cogitar do indivíduo a êle dedicado, ou seja do "trabalhador", num sentido mais restrito que o indicado acima, isto é, do individuo que trabalha, ou se prepara para trabalhar, sob a dependência de um outro, por isto que este trabalhador subordinado necessita mais da proteção das leis sociais, que o trabalhador autônomo, por ser evidentemente maior a sua hipossuficiencia (18-a).

(18-a) O Direito Social só cogita da hipossuficiencia ou debilidade económica absoluta, que é a definida por nós acima. A debilidade económica relativa, isto é, o fáto de ser apenas um ser economicamente mais fraco do que um outro, é objeto, não do Direito Social, mas do Direito Económico, v. g., a posição do pequeno capitalista, do pequeno industrial ou do pequeno comerciante, em frente ao grande capitalista, ao grande industrial ou ao grande comerciante. 
22 - Ora, estes trabalhadores subordinados, que chamaremos, de acôrdo com a técnica moderna do nosso Direito, de empregados, já antes que as leis sociais tivessem sido criadas para protegê-los, haviam encontrado um meio de autoproteção, (19) procurando suprir a sua fraqueza econômica, pela sua união o que lhes permitia opôr-se aos patrões, (que na técnica moderna chamamos de "emprega(lores"), por meio das coalisões, paredes, etc.

Pois bem. Foi justamente desta união de esforços dos economicamente fracos, que os tornou, primeiro física, e depois politicamente mais fortes, que surgiram as primeiras leis sociais eficientes, cujo primeiro objetivo foi exatamente legalizar estas uniões de empregados, antes proibidas pela lei. Legalizadas estas uniões, sob a forma dos sindicatos, por seu intermédio ainda, foram obtidas novas leis sociais, dispondo sobre outros interesses da classe economicamente mais fraca.

Por sua vez, os empregadores se uniram tambem, para contrabalançar com arma idêntica e com um refôrço de seu poder econômico, a maior potência dos empregados. Mais tarde, a intervenção do Estado forçou a união dos sindicatos de empregados e de empregadores, em órgãos mixtos, as corporações, visando substituir o seu antagonismo pela sua colaboração.

Assim sendo, é facil ver que, residindo na união dos trabalhadores, a razão de sua fôrça, união esta tambem adotada pelos empregadores, está lógica e historicamente justificado que o Direito Social se ocupe primeiramente com os empregados e empregadores, considerados coletivamente, para depois se preocupar com êles individualmente considerados.

Ao conjunto das leis sociais que consideram os empregados e empregadores coletivamente, principalmente na

(19) Este termo é usado por Pergolesi, Trattato di Diritto del Lavoro, Padua, 1939, I/pg. 50. 
forma de sindicatos e corporações, denominado Direito Corporativo ou Direito Social Coletivo.

Aí estudamos sucessivamente: as associações profissionais, que são as formas mais gerais das uniões de empregados e empregadores; o sindicalismo, conjunto das teorias sobre os sindicatos, que são as formas especificas dessas uniões; as corporações, que visam pôr em contacto os sindicatos, só de empregados, com os sindicatos, só de empregadores, numa única instituição; o Conselho da Economia Nacional, a que em nosso sistema constitucional cabe promover a organização corporativa do país; os contratos coletivos de trabalho, que são acôrdos sobre normas reguladoras das condições de trabalho, celebrados entre sindicatos de empregados e sindicatos de empregadores; os conflitos do trabalho entre empregados e empregadores, cujas formas principais são a "gréve" e o "lock-out" e os meios de prevení-los ou de resolvê-los, que são as comissões mixtas de conciliação e arbitragem, as juntas de conciliação $e$ julgamento, e de um modo geral, a Justiça do Trabalho (20).

23 - Ao conjunto das leis que consideram individualmente o empregado e o empregador, unidos numa relação contratual, dou o nome de Direito do Trabalho, ou Direito Social Especifico.

Estas leis são em primeiro lugar, como é óbvio, as referentes ao contrato individual de trabalho, e depois á regulamentação ou tutela do trabalho e aos seguros sociais, constituindo o que chamo Direito do Trabalho propriamente dito, por isso que regulam relações fundadas num contrato individual de trabalho, embora este contrato possa ser pre-

(20) A colocação da Justiça do Trabalho no Direito Corporativo é controvertida, por isso que ela depende da organização que venha a ter essa Justiça, devendo incluir-se no Direito Administrativo do Trabalho, ou talvez melhor, num Direito Judiciário do Trabalho, si não tiver forma paritária, isto é, não fôr composta com representantes dos empregados e dos empregadores, como preceituava a constituição de 1934, no art. 124 e determina atualmente o decreto lei n. 1.237, de 2 de maio de 1939 . 
sente (como no caso da tutela do trabalho), passado (como no caso de alguns dos seguros sociais) ou futuro (como no caso da aprendizagem). Vêm depois as concernentes à organização e funcionamento das instituições administrativas incumbidas de fiscalizarem e promoverem o cumprimento das leis sociais, formando o que se póde chamar o Direito Administrativo do Trabalho.

Coloquei no Direito do Trabalho o estudo das leis sobre os seguros sociais, ou o conjunto de medidas tendentes a estabelecer a previsão, mais ou menos obrigatória, dos principais riscos a que está sujeito o indivíduo, como sejam: o desemprêgo, a doença, a invalidez, os acidentes do trabalho, a maternidade, a morte, etc., assim como das instituições geralmente autárquicas, a que incumbe a organização prática dessa previsão. A colocação dos seguros sociais no Direito do Trabalho è assunto muito controvertido, havendo quem prefira fazer com o seu estudo um ramo à parte do Direito Social. Segui, porém, a lição de Mario dE LA Cueva, para quem: “A previsão social não se restringe exclusivamente aos trabalhadores, mas se aplica a todas as classes sociais, porém, aplicada áqueles, não é senão uma consequência da posição do operário nos fenómenos da produção e deriva da existência de um (32-a) contrato de trabalho" E tal é o sistema do nosso Direito Social.

Até aquí, só cogitámos das leis sociais no âmbito de um determinado país, no caso, o nosso. Elas podem, entretanto, ser consideradas tambem do ponto de vista internacional, formando o chamado Direito Internacional do Trabalho. $\mathrm{E}$ isto porque, trazendo os benefícios concedidos aos empregados encargos para os empregadores, encargos estes que se refletem no custo de produção, é absolutamente impossivel a um país introduzir grandes melhoramentos na situação dos seus empregados, principalmente do ponto de vista econômico, sem se vêr seriamente prejudicado pela concurrência dos demais paises de atividade econômica

(32-a) Derecho Mexicano del Trabajo, Mexico, 1938, pg. 13. 
semelhante, cuja produção terá ficado mais barata. Além disto, deslocando-se os trabalhadores de um para outro país, é possivel a ocorrência de conflitos de leis em matéria de trabalho, assunto este tambem da alçada do Direito Internacional do Trabalho.

Além disto, as leis de outros países pódem ser estudadas sob o ponto de vista comparativo, o que nos dará um Direito Comparado do Trabalho.

Em algumas legislações, como a italiana, poder-se-ia cogitar tambem de um Direito Penal do Trabalho, de um Direito Tributário do Trabalho e até mesmo de um Direito Colonial do Trabalho, o que, evidentemente, não é, pelo menos por enquanto, o caso do nosso Direito.

24 - Feito este estudo das leis sociais atinentes aos trabalhadores propriamente ditos, cumprirá estudar, em último lugar, as leis sociais aplicaveis à generalidade dos indivíduos economicamente fracos, e que integram (21) a parte de nossa disciplina que denomino Direito Social propriamente dito ou Direito Social Genérico. E o chamo assim porque se refere precipuamente à ação social do Estado em favor dos hipossuficientes, com carater mais geral. $O$ exercício desta atividade social do Estado deve ser encarado

(21) Fantinl, Legislazione Corporativa del Lavoro, Vallardi, Milão, 1938. pg. 15 - "Enquanto a legislação do trabalho se refere, em suma, direta e exclusivamente ao trabalhador, a legislação social se refere a categorias sociais indeterminadas que necessitam de assistência". No mesmo sentido quasi Sanseverino, op. cit., pg. 17: "Por legislação social se vem a entender o complexo das normas tendo o fim de tutelar o trabalhador em toda outra circunstância possivel que não seja a das suas relações contratuais com a empresa de que depende. Neste caso a expressão "trabalhador" é considerada num sentido mais amplo do que o próprio ao direito do trabalho, enquanto não se tem sempre o trabaihador no estado efetivo e atual, mas tambem só no estado potencial (seguro contra a desocupação) ou pertencente ao passado (seguro contra a invalidez e a velhice)" E ainda: "O Direito do Trabalho entende tutelar o trabalhador enquanto tal, nas relações contratuais com o empregador, enquanto a legislação social, compreendendo a chamada "política administrativa do trabalho" entende tutelar o trabalhador enquanto homem, em algumas das suas fundamentais exigências materiais e espirituais" 
nos diversos pontos de vista sob os quais sóe manifestarse, isto é: na ordem demográfica, referente aos problemas da população; na ordem eugênica e higiênica referente ao aperfeiçoamento da raça; na ordem econômica, referente ao melhoramento das condições materiais dos hipossuficientes; na ordem familiar, referente à conservação e desenvolvimento do espirito de família; na ordem educacional, referente à formação física, intelectual, moral, estética, social, civica e religiosa dos individuos economicamente fracos.

25 - Esquematizando, poderiamos dizer que, em ultima análise, o Direito Social é "o sistema legal de proteção aos economicamente fracos" Esta proteção póde consistir numa autoproteção, quando resulta principalmente da união, da organização desses individuos: é o caso do Direito Corporativo; ou numa heteroproteção, quando resulta precipuamente da ação do Estado, embora em certos casos com pequena participação dos hipossuficientes. Esta ação pode ser exercida de um modo específico, isto é, em relação aos trabalhadores subordinados e teremos o Direito do Trabalho; ou de um modo genérico, em relação a todos os individuos economicamente débeis e teremos o Direito Social propriamente dito $(22)$.

(22) Radruch, Introdución a la Ciência del Derecho, Madrid, 1930, pg. 108: "Se quizessemos traduzir em linguagem jurídica a enorme revolução que estamos presenciando nos fatos e nas idéias, diriamos que a tendência para um "Direito Social", cada vez mais vai socavando a separação rígida entre Direito Privado e Direito Público, entre Direito Civil e Direito Administrativo, entre contrato e lei : ambos os tipos de Direito penetram um no outro reciprocamente, dando lugar à aparição de novos campos jurídicos, que não podem ser atribuidos, nem ao Direito público nem ao privado, senão que representam um Direito inteiramente novo, de um terceiro tipo: o Direito econômico e operário.

Do Direito privado só se levavam em conta os individuos contratantes, sem se cogitar da comunidade, admitindo-se que os interesses privados se ajustariam espontaneamente em vista da utilidade comum. A guerra desmentiu esta crença, fazendo surgir o Direito Econômico que observa as relações econômicas predominantemente do ponto de vista do interesse econômico geral, da produtividade da 
Assim, teríamos o seguinte esquema:

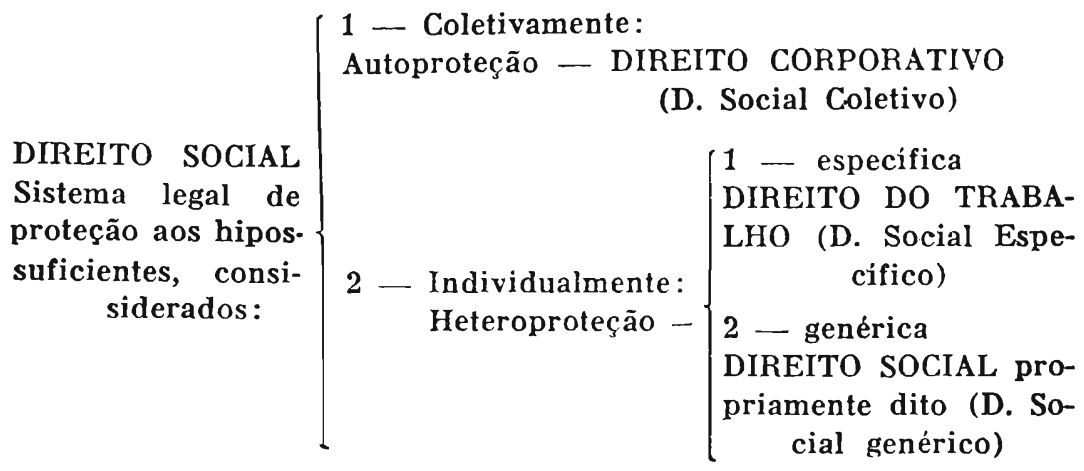

economia: é o Direito da Economia organizada, como foi a economia de guerra. Em consequência a propriedade privada e a liberdade contratual não volverão mais a alcançar o nimbo jusnaturalista da intangibilidade que as caracterizou até então, como fez a Constituição de Weimar, que as garantia mas somente "na forma das leis". Assim, os direitos, como o paterno v. g. são condicionados por deveres, cujo exercício é tutelado pelo Estado. Socialização significa a participação capitalista decisiva do Estado ou do Municipio numa empresa privada (o que então se chama empresa económica mixta), e, finalmente, a "sindicalização obrigatória", isto é, a formacão de associações obrigatórias de todas as empresas de um ramo econômico, com uma administração autônoma, sob a inspecção estatal. E' este o tipo escolhido para os casos mais importantes de socialização.

Mas, não só o Direito público invadiu a economia, como a economia privada penetrou na vida politica. Os pais da Constituição de Weimar abrigavam a idéia de estabelecer, além da Constituição política, uma Constituição social, isto é. além de tratar democraticamente, de individuos livres e iguais, tambem de elementos das atividades econômicas e das classes sociais.

$\mathrm{E}^{\prime}$ discutivel se o direito econômico é um novo ramo juridico ou apenas um novo método do pensamento juridico, aplicavel aos seus mais variados campos. Pelo contrário, o Direilo operário constitue uma disciplina nova. Enquanto o Direito econômico considera as relações económicas do ponto de vista da produtividade, o Direito operário as focaliza segundo o critério da proteção do debil perante o poderoso endinheirado. O primeiro se inclina mais para o ponto de vida do empresário; o segundo, preponderantemente para o interesse do operário. Dai, entrarem em luta, como na questão do dia de oito horas.

O Direito operário é uma reação contra o espirito do Direito Civil. Este reconhece só "pessoas", sujeitos juridicos, que contratam entre si mediante livres decisões de ambas as partes; e nada sabe do trabalhador, situado numa posição de inferioridade perante o em- 
presário. Nada sabe tambem da solidariedade do proletariado, que compara ou nivela esta inferioridade do poder do operário individual perante o patrão; nem das grandes associações profissionais que mediante seus contratos coletivos de trabalho, são quem propriamente os conclue, senão que mira exclusivamente aos contratantes individuais e ao contrato de trabalho singular. Nada sabe, por fim, da unidade de trabalho da empresa.

A essência do Direito operário consiste, cabalmente, em sua maior proximidade à vida. Não vê só pessoas, como o Direito Civil, senão empresários, operários, empregados; não só pessoas individuais, senão associações e empresas; não só os contratos livres, senão tambem as graves lutas econômicas que constituem o fundo destes supostos contratos livres.

A missão do novo Direito Operário se estabelece em conceder validade aos direitos humanos do operário e estruturar o vínculo do trabalho como uma relação jurídico-pessoal, sobre um novo plano, sobre o plano da liberdade pessoal. O Direito Operário é uma organização contra os perigos da liberdade contratual jurídico-formal no campo das relações de trabalho; ora pondo imediatamente limites legais a dita liberdade, graças a preceitos "taxativos" ou "imperativos" (proteção do operário); ou ligando o contrato de trabalho entre o operário e o patrão aos contratos cletivos cncluidos entre as associações de empresários e de operários (contratos de tarifas); bem, concedendo ineludiveis efeitos jurídico-públicos ao fato do contrato de trabalho (seguros sociais); bem, finalmente, promovendo o ajuste de contratos coletivos de trabalho, estabelecendo medidas de previsão para o caso de que não se obtenha seu ajuste e tratando de remediar ?. insegurança de posição produzida pela liberdade contratual (Bolsas de trabalhos e assistência aos desempregados)". 